\title{
SAFETY FACTORS FOR CFRP STRENGTHENING IN BENDING OF REINFORCED CONCRETE BRIDGES
}

\author{
Caterina Trentin, Joan R. Casas* \\ Construction Engineering Department.Technical University of Catalonia- BARCELONATECH \\ C/ Jordi Girona 1-3, Campus Nord, Mòdul C1 \\ 08034- Barcelona, SPAIN
}

\begin{abstract}
$\underline{\text { ABSTRACT }}$
Concerning the strengthening in bending of reinforced concrete bridge decks, the use of fiber reinforced polymers (FRP) has increased due to its easy application and excellent mechanical and chemical properties. However, due to the lack of codes and standards and the lack of experience in the long term behavior, uncertainties exist in the calculation bases along the dimensioning of this reinforcement and more precisely in the partial coefficients of safety to be adopted for the material properties. As a consequence, bridge engineers are reluctant to use composite materials in the strengthening of damaged reinforced concrete bridge decks. To try to overcome this problem, this paper describes the methodology for a reliability-based calibration of the partial safety factors to be used for the CFRP material in the design of strengthening to bending. The method requires the definition of a response model jointly with the statistical definition of the model error. This is discussed in the first part of the paper. The reliability-based procedure is developed based on the design equation and the corresponding model. A simple set of partial safety factors is finally proposed for a representative population of $\mathrm{RC}$ bridges. The conclusions highlight the importance of incorporating the model error in the calibration. In addition, the paper shows how in some cases it is not feasible to design a flexural strengthening by using CFRP.
\end{abstract}

Keywords: safety factor, carbon fiber composites, bridge deck, strengthening, model error, bending

\section{Introduction}

Over the last 20 years, the use of fiber-reinforced polymers (FRP) for the strengthening, repair and seismic retrofit of existing structures has widely increased. This has been possible thanks to the huge research activity conducted, focused mainly on the FRPs mechanical characteristics and capacity on collaborating with other materials largely used in civil engineering, such as reinforced concrete, wood "corresponding author: joan.ramon.casas@upc.edu, +34 934016513 
and masonry. The strengthening with FRPs results very attractive since the composites present high mechanical characteristics, high properties as thermic and electric insulators, immunity to corrosion and efficiency of application. The use of FRPs is moreover not invasive, since the composites are bonded externally on existing structures in form of laminates, without altering heavily the facility configuration, size and weight. The use of externally bonded plates to strengthen RC beams in flexure has been well researched [1].

The design process of a new concrete structure or the strengthening of an existing one should verify:

$$
R_{d} \geq S_{d}
$$

Being $R_{d}$ and $S_{d}$ the design values of the resistance and actions respectively. When using a semiprobabilistic approach, the design values for a structural concrete element are calculated as:

$$
\begin{aligned}
& R_{d}=R\left(\frac{f_{c k}}{\gamma_{c}} ; \frac{f_{y k}}{\gamma_{s}}\right) \\
& S_{d}=\sum_{i=1}^{n} \gamma_{f i} S_{k i}=\sum_{i=1}^{n} \gamma_{f i} S\left(Q_{k i}\right)
\end{aligned}
$$

where:

$$
\begin{aligned}
S_{k i} & =\text { characteristic value of the action " } \mathrm{i} \text { ", due to load } Q_{k i} \\
\gamma_{f i} & =\text { partial safety factor of action " } \mathrm{i} \text { " } \\
f_{c k} & =\text { characteristic strength of concrete. } \\
\gamma_{c} & =\text { partial safety factor of concrete strength } \\
f_{y k} & =\text { characteristic strength of reinforcing/prestressing steel } \\
\gamma_{s} & =\text { partial safety factor of steel strength. }
\end{aligned}
$$

If the partial safety factors have been appropriately calibrated, then a required level of safety (defined during the calibration process) is assured by verification of equation (1). The Codes and Standards dealing with the design of new concrete structures provide appropriate values of the partial safety factors for concrete and steel. However, when dealing with the retrofit of an existing reinforced concrete element, to be strengthened in bending through the bonding of FRP in the tensile zone, the question arises about the safety factor to be used regarding the composite material. 
It is not easy to establish a value for the safety factors in the design or assessment of structural members, whatever the resisting mechanism they work through. Indeed, safety factor values are often based on the experience of competent designers or on deterministic approaches and are rarely supported by statistical studies. Even though this is not a major problem for easy predictable resisting models, imprecise safety factor estimates may lead to significant consequences in the case of more complicated resisting models, which are affected by high levels of uncertainty.

This is the case of the intermediate crack-induced (IC) debonding models, developed to predict one of the most problematic failure-modes related to the flexural strengthening of reinforced-concrete members with FRPs. The IC debonding initiates in the vicinity of intermediate flexural or mixed flexural-shear cracks that propagate in the superficial concrete layer to which the composite plates are bonded. Once the cracks arrive at the nearest plate-end, the FRP is detached from the substrate and the composite action is lost.

The debonding generally occurs before the ultimate tensile stress in the FRP or in the concrete and steel is reached. Therefore, it has often to be considered as the critical failure mode when designing the strengthening. Over the last years, this phenomenon has been studied closely, and more and more models predicting the FRP IC debonding have been developed [2,3,4]. However, the uncertainty underpinning the issue is hardly impossible to remove. This is why both a correct estimate of the safety factors and a better knowledge of the accuracy of the models are extremely important. The calculation of the safety factors should be made through a reliability-based approach, to consider as best as possible all the uncertainties connected to the adopted materials, the acting loads and the applied analytical model.

Codes and recommendations define safety factors for the design of FRP-strengthened concrete elements. However, detailed probabilistic information to support the selected resistance factors is lacking and the safety factor is mainly fixed based on the experience and engineering judgment. The aim of the present study is to propose objective and appropriate reliability-based design equations with properly calibrated safety factors that can be used during the design of a strengthening using carbon fiber reinforced polymer (CFRP) to enhance the flexural capacity of decks of existing bridges.

The reliability of reinforced concrete elements, externally bonded with FRPs was analyzed for the first time by Triantafillou and Plevris in 1992 [5], and then faced again in Plevris et al. in 1995 [6]. In the latter study, a Monte Carlo simulation was conducted in order to determine the strength reduction factor for a typical cross-section of a RC beam, strengthened in bending with CFRP laminates. Various design cases were considered, modifying conveniently the acting parameters. Only the failure modes 
for CFRP rupture and concrete crushing were analyzed, considering that uncertainties in debonding failure could be substantially limited by a high level of control when applying the CFRP plate to the soffit of the beam.

Okeil et al. [7] conducted a similar study in 2002, this time for girder bridges. The reliability of three simply-supported reinforced concrete bridges, with different levels of steel corrosion, was investigated in order to determine a resistance model for strengthened $\mathrm{RC}$ beams and estimate a strength reduction design factor. A Monte Carlo simulation led to the calculation of the resisting moment, while a firstorder reliability method was used to obtain the reliability index. Again the CFRP rupture failure mode was modeled, without considering any other type of failure, such as shear or debonding.

Atadero et al. [8] obtained the reliability indices of FRP strengthened bridge decks. The ultimate moment capacity of the slab was determined assuming a linear strain distribution across the slab crosssection with failure assumed to occur at first yield of the steel reinforcement set at $0.2 \%$ rather than modes of concrete crushing or debonding of the bonded FRP.

A more detailed procedure for calibrating safety factors when designing with FRP was proposed by Monti and Santini [9]. Their aim was to give an easy and general framework, that could be followed regardless of the different types of applications and strengthening used (flexure, shear, ...). Unlikely, their method is difficult to solve, mainly because thought for different limit states together with many multiple load and capacity scenarios, so that a simultaneous calibration should be done, implying a remarkable computational effort.

Two are the main drawbacks of these studies:

- they consider only the strengthening with prefabricated systems, neglecting the variability that can affect the problem when a wet-lay up system is applied

- $\quad$ they do not take into account the real critical failure mode, i.e., the debonding.

These problems were known by Atadero and Karbhari [10], who proposed a methodology for the calibration of the preliminary resistance factors for externally-bonded wet-lay up CFRP, by following the load and factor design (LRFD) as given by the AASHTO Code. The flexural strengthening of 20 reinforced-concrete T-beams bridge girders was designed hypothesizing different types of applications, accounting for the environmental exposure and aiming to three different target reliability levels, $\beta=2,5,3,0$ and 3,5. The collapse mode investigated was the debonding failure. The authors proposed different values of the composite safety factor for given values of the general resistance factors, pooling the analyzed bridges in different design groups, depending on the percent of steel loss. As observed by Ceci et al. [4], the main drawback of the procedure followed by Atadero and Karbhari is that only the randomness of the input parameters is considered and there is not a specific accounting for the modeling uncertainties (or epistemic uncertainties). The variability related to the application of 
the CFRP was considered only in terms of the coefficient of variation (COV) of the most critical composite property, from which the composite partial safety factor depends. Moreover, they stressed out the necessity to consider the high degree of variability related to the use of wet-lay up systems. To account for the under-prediction of debonding strain using a simplified approach, they applied an empirical factor of 1.5 to the predicted debonding strain. This could be considered as a bias factor. However, they do not consider the uncertainty in the prediction model and therefore, no coefficient of variation was considered. Pham and Al-Mahaidi [11] calculated the reduction factors for the strength of retrofitted members based on the method outlined in Annex $\mathrm{C}$ of Eurocode [12]. In this simplified analysis, without accounting for the load variation and other uncertainties, they assumed a sensitivity factor for resistance equal to 0.8 and a target reliability index of 3.25. For those values they obtained a capacity reduction factor of 0.6 for full composite strength (no debond) and intermediate span debond. A factor of 0.5 was obtained for end debonding.

The final objective of the present study is to propose appropriate reliability-based design equations with properly calibrated safety factors for flexural strengthened reinforced-concrete members at the Ultimate Limit State, attempting to address all the issues discussed. The strengthening will be designed both for prefabricated and wet-lay up systems and the so-called "model error" modelled by a random variable will be introduced in the reliability-based calibration procedure [13]. In a recent study, Casas and Chambi [14] calibrated a set of partial safety factors for CFRP wrapped bridge piers subject to axial-bending actions by introducing the model error. The importance of taking into account the model error in the strengthening to bending will be further discussed in chapter 5 . The statistical analysis of selected existing crack-induced debonding models will provide the necessary input to calibrate appropriate safety factors that should be applied in conjunction with the selected models. In this way, future design codes could provide to design engineers the tools necessary to use CFRP strengthening schemes that would lead to uniform, consistent and economical safety levels.

\section{Model assessment}

To perform a proper reliability-based calibration, first of all, it is necessary to define accurately the resisting mechanism analyzed. Indeed, it is extremely important that both the design equations and the limit state function (LSF) developed represent as best as possible the behavior of the strengthened member when subject to bending. For an appropriate calibration, the first step is to derive the most accurate design equations for the debonding mechanism in CFRP strengthened members, based on the available theoretical models, jointly with the statistical characterization of the random variable "model 
error". This random variable is defined as the ratio of the actual debonding failure load to the load predicted by the model $\left(P_{\text {exp. }} / P_{\text {pred. }}\right.$ ) (see figure 1$)$. The model error should be statistically characterized by defining the type of random variable and its mean value (or bias ratio) and standard deviation (or coefficient of variation).

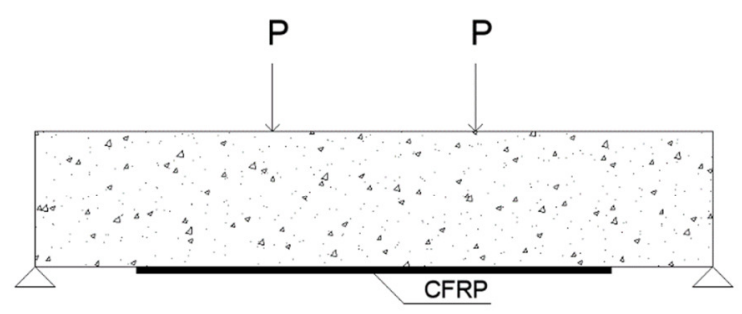

Figure 1. Example of bending test made through the application of two concentrated external forces (two-point bending).

Various models have been proposed to represent the IC debonding. Said and $\mathrm{Wu}$ [15] investigated the performance and accuracy of five models available in code provisions and other literature. Test results of 200 flexural specimens with IC debonding failures collected from the existing literature were used in the comparison. Finally, based on the statistical analysis a simple model is proposed which provides the best accuracy, with a model error with a bias ratio equal to 1.0 and a COV of $9.2 \%$.

In the study presented in [4], a statistical analysis of several proposed models for end debonding as well as intermediate crack-induced debonding modes of failure are studied for beams in flexure. Two different databases were assembled. The first database contains the results of four point bending tests performed to study the behavior of the FRP-concrete bond at the end of the FRP sheet. The second database which includes four point bending tests, three point bending tests and one point loading tests, was created to examine intermediate crack-induced debonding. The design models which gave the lowest COV while showing consistent results for end debonding for both prepeg and wet lay-up installations were the Teng and Yao [16] and the Casas and Pascual model [17]. One clear advantage of the Casas and Pascual model is that it can be used for end debonding and also for intermediate crack-induced debonding. Additionally, Casas and Pascual model takes into consideration the interaction between FRP, the resin and the concrete and therefore takes into account the properties of the resin in the debonding mechanism. Generally, debonding models are checked in specimens of small size, which may not represent properly the real structures where FRP strengthening is applied. 
Available tests show that the maximum strain in the FRP at debonding is related to the dimensions of the specimens [17]. The model proposed by Casas and Pascual also accounts for the dimensions of the strengthened element in terms of cross-section depth and therefore is more suitable for the cases analyzed here, i.e., bridge girders with large cross-section depths. As shown in [4], the statistical analysis of this model provides a model error with a bias ratio equal to 1.8 and COV of $23 \%$.

The calibration procedure will be carried out for 2 models: Said and Wu [15] and Casas and Pascual [17]. This will give the possibility to compare the sensitivity of the final results with the adopted model, taking into account that one is calibrated over the mean value and the other with the characteristic value (95\% fractile) of the experimental results. This could help to better understand the results obtained, given that there are no previous cases of calibration of safety factors for IC debonding where the model error variable is considered and to realize how the model error is a variable of paramount importance in the reliability-based calibration.

The failure mode considered in the analysis (debonding) also makes a constraint on the response model in bending to be used in the analyzed bridge sections. In most cases, and particularly in the case of T-shape reinforced-concrete elements, it is known that debonding occurs before the ultimate compressive strength of the concrete is reached. Moreover, usually concrete strains in the compression zone are so low that the simplified rectangular stress-block cannot be used and it is necessary to refer to another stress-strain relation. Therefore, it was decided to develop a simplified linear concrete stress-strain relation. This allows to simplify the design equations and the limit state function, reducing significantly the computational effort otherwise required. 


\section{Calibration}

To start with the process of calibration and once the selection of the theoretical model and corresponding uncertainty are done, the next step is to define the range of possible structures/elements where the obtained safety factors will be of application. Therefore, the bridge population is presented next.

\subsection{Bridge population}

In order to consider an appropriate range of geometries to calibrate the safety factors, seven different reinforced concrete bridges are studied. They cover an important number of short and medium span reinforced concrete bridges present in actual highways and railways. Therefore, a large amount of the concrete bridge population is taken into account.

In order to simplify the references to the bridges, the following notation will be used (see Table 1 and Table 2). The first letter of the abbreviation indicates the shape of its cross-section:

- "B”, which means "beam", for girder bridges;

- "S", which means "slab", for slab bridges.

The first symbol is followed by numbers, which represent the span lengths in meters. There will be two digits for simply supported bridges and four digits for continuous bridges. Eventually, the last two letters "RC" state the material of the bridge, which is reinforced concrete.

The concrete has a characteristic compressive strength equal to $f_{c k}=20 M P a$, while the characteristic yielding strength of the steel is $f_{y k}=216 \mathrm{MPa}$. These values are low because they correspond to materials used in the 1940's and 1950' (Table 3). It should be pointed out that those old bridges are clear candidates to be strengthened due to lack of resistance for actual traffic conditions.

\begin{tabular}{ccccccc}
\hline Bridge & $\begin{array}{c}\text { Deck width } \\
(\mathrm{m})\end{array}$ & $\begin{array}{c}\text { Number of } \\
\text { girders }\end{array}$ & $\begin{array}{c}\text { Girder } \\
\text { spacing }(\mathrm{m})\end{array}$ & $\begin{array}{c}\text { Web width } \\
(\mathrm{mm})\end{array}$ & $\begin{array}{c}\text { Girder depth } \\
(\mathrm{mm})\end{array}$ & $\begin{array}{c}\text { Slab depth } \\
(\mathrm{mm})\end{array}$ \\
\hline B10RC & 9.35 & 6 & 1.50 & 350 & 1000 & 200 \\
B12RC & 9.35 & 6 & 1.50 & 350 & 1200 & 200 \\
B16RC & 9.35 & 6 & 1.50 & 350 & 1600 & 200 \\
B20RC & 9.35 & 6 & 1.50 & 350 & 2000 & 200 \\
\hline
\end{tabular}

Table 1. Definition of the girder bridges. 


\begin{tabular}{ccccc}
\hline Bridge & $\begin{array}{c}\text { Deck width } \\
(\mathrm{m})\end{array}$ & $\begin{array}{c}\text { Deck depth } \\
(\mathrm{mm})\end{array}$ & $\begin{array}{c}\text { box width } \\
(\mathrm{m})\end{array}$ & $\begin{array}{c}\text { flange width } \\
(\mathrm{m})\end{array}$ \\
\hline S10RC & 12 & 1000 & 8.8 & 1.3 \\
S1015RC & 12 & 1300 & 8.4 & 1.3 \\
S1520RC & 11 & 1600 & 5.7 & 2.3 \\
\hline
\end{tabular}

Table 2. Geometric definition of the slab bridges.

\begin{tabular}{ll}
\hline Concrete & \\
\hline Characteristic compressive strength $[\mathrm{MPa}]$ & 20 \\
Specific weight $\left[\mathrm{KN} / \mathrm{m}^{\wedge} 3\right]$ & 25 \\
\hline Steel & \\
\hline Characteristic yielding strength $[\mathrm{MPa}]$ & 216 \\
\hline
\end{tabular}

Table 3. Concrete and steel properties.

\subsubsection{Girder bridges}

The analyzed bridges are simply supported and have the same cross-section width, which counts six principal beams. There are three transverse beams, two at the ends and one at the mid-span. As an example, Figure 2 represents the cross-section of bridge B10RC. The bridges differ in span length and principal and transverse beams depth as shown in Table 1.

As first step, it is checked if the bridges can withstand the actual traffic loads as required by the Eurocode [18]. The results are summarized in table 4 for the mid-span section of a single beam. The analysis shows that the design values of the bending moment due to the permanent loads and liveload $\left(\mathrm{M}_{\mathrm{sd}}\right)$ are much higher than the design values of the resisting moment $\left(\mathrm{M}_{\mathrm{rdold}}\right)$ calculated with the actual reinforcement $\left(\mathrm{A}_{\text {sold }}\right)$. Therefore, it is necessary to increment the reinforcing steel up to a new value $\left(\mathrm{A}_{\text {snew }}\right)$ to get an adequate resisting moment $\left(\mathrm{M}_{\text {rdnew }}\right)$. This increment has an average value of $32 \%$. In the calculation, the relevant safety factors as given in the Eurocode were used. 


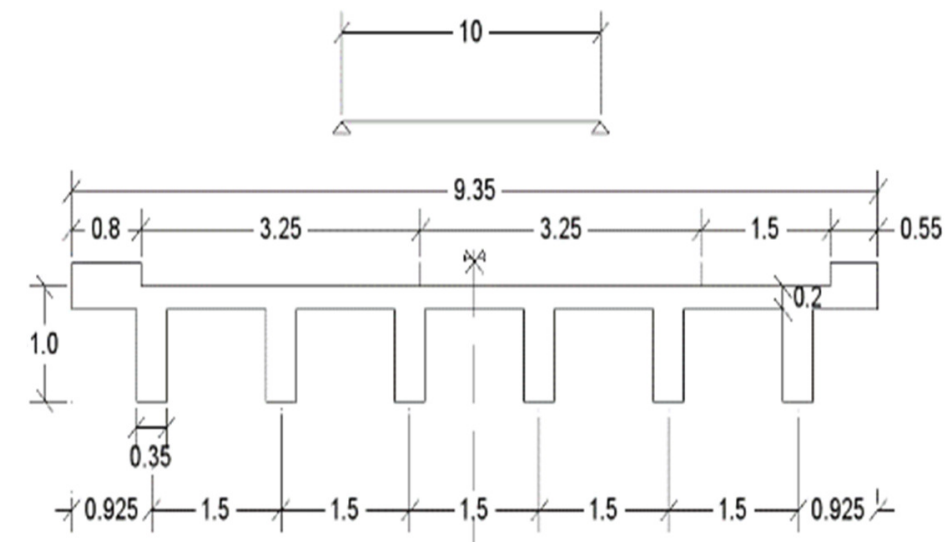

Figure 2. B10RC cross-section (dimensions in $\mathrm{m}$ ).

\begin{tabular}{lcccccc}
\hline Bridge & $\begin{array}{c}\boldsymbol{M}_{\boldsymbol{s} \boldsymbol{d}} \\
(\mathrm{KNm})\end{array}$ & $\begin{array}{c}\boldsymbol{M}_{\boldsymbol{R} \text { dold }} \\
(\mathrm{KNm})\end{array}$ & $\begin{array}{c}\boldsymbol{A}_{\text {sold }} \\
\left(\mathrm{cm}^{2}\right)\end{array}$ & $\begin{array}{c}\boldsymbol{M}_{\boldsymbol{R} \text { dnew }} \\
(\mathrm{KNm})\end{array}$ & $\begin{array}{c}\boldsymbol{A}_{\text {snew }} \\
\left(\mathrm{cm}^{2}\right)\end{array}$ & $\begin{array}{c}\text { Tensile } \\
\text { steel } \\
\text { increment } \\
(\%)\end{array}$ \\
\hline B10RC & 5572 & 4396 & 255 & 6060 & 370 & 45.10 \\
B12RC & 7647 & 6390 & 295 & 7722 & 386 & 30.85 \\
B16RC & 13016 & 10836 & 386 & 13296 & 489 & 26.68 \\
B20RC & 20296 & 17208 & 488 & 21150 & 611 & 25.20 \\
\hline
\end{tabular}

Table 4. Old and new resisting moments of the girder bridges.

\subsubsection{Slab bridges}

The slab bridges analyzed are shown in figure 3 . One is simply supported with a single span of 10 $\mathrm{m}$, while the others are 3-span continuous over supports with main span of 15 and $20 \mathrm{~m}$. The last one has voided cross-section to decrease the self-weight. Again, in table 5 is shown the actual disposed reinforcement calculated with the existing standards at the time of construction, and the necessary reinforcement according to the Eurocode [18]. The mid-span sections subject to positive moment are considered for strengthening 

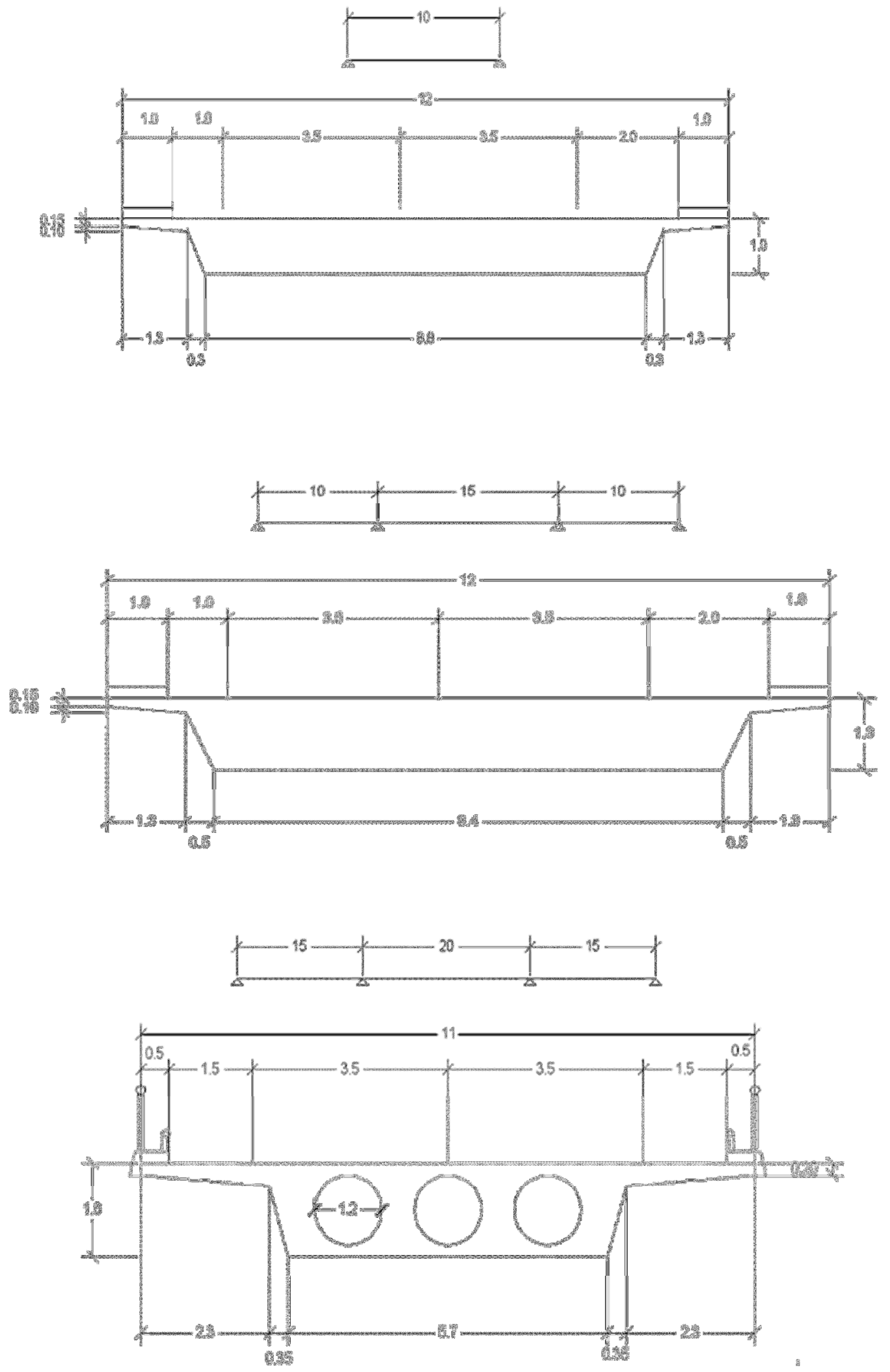

Figure 3. Slab bridges: spans and cross-sections (dimensions in m). 


\begin{tabular}{lccccc}
\hline Bridge & $\begin{array}{c}\boldsymbol{M}_{\boldsymbol{s} \boldsymbol{d}} \\
(\mathrm{KNm})\end{array}$ & $\begin{array}{c}\boldsymbol{M}_{\text {Rdold }} \\
(\mathrm{KNm})\end{array}$ & $\begin{array}{c}\boldsymbol{A}_{\text {sold }} \\
\left(\mathrm{cm}^{2}\right)\end{array}$ & $\begin{array}{c}\boldsymbol{M}_{\text {Rdnew }} \\
(\mathrm{KNm})\end{array}$ & $\begin{array}{c}\boldsymbol{A}_{\boldsymbol{s}} \text { new } \\
\left(\mathrm{cm}^{2}\right)\end{array}$ \\
\hline S10RC & 8698 & 6519 & 388 & 9179 & 570 \\
S1015RC & 9625 & 6899 & 303 & 9878 & 446 \\
S1520RC & 12289 & 9479 & 335 & 13599 & 493 \\
\hline
\end{tabular}

Table 5. Old and new resisting moments of the slab bridges.

\subsection{IC debonding models}

As mentioned before, the calibration procedure will be carried out for 2 models: Said and Wu [15] and Casas and Pascual [17]. Before proceeding with the design and calibration procedure, it is necessary to recall briefly their main characteristics.

\subsubsection{Casas and Pascual (2007)}

Casas and Pascual's model can be used both as IC and plate-end debonding model. It differs from other existing models mainly because it considers the properties of the bond layer and accounts for the dimensions of the strengthened element, in terms of cross-section depth. Since the analyzed RC members are bridge girders, i.e. elements with a large cross-section depth, it is possible to refer to the simplified single-crack model proposed by Casas and Pascual. Indeed, in these members, the distance between bending cracks (s) is larger than the effective bond length of the FRP $\left(L_{e}\right)$; hence, the condition at one crack is independent of the situation at the closer cracks.

The maximum shear stress before IC debonding occurs $\left(\tau_{\max }\right)$ is given by:

$$
T_{u}=\tau_{\max } L_{e}
$$

where $\tau_{\max }=\eta \sqrt{f_{c}}$, with $f_{c}=$ compressive strength of concrete, and $\eta=0,996$, coefficient experimentally determined.

If the stiffness of the strengthened concrete element is higher than the FRP stiffness, the effective bond-length $L_{e}$ is given by: 


$$
L_{e}=\sqrt{\frac{k_{f}}{g_{b}}}
$$

where

- $\quad k_{f}=E_{f} t_{f}$ is the stiffness of the FRP for unit length;

- $\quad g_{b}=\frac{g_{r} g_{c}}{g_{r}+g_{c}}$ is the shear joint stiffness of concrete plus adhesive resin;

- $g_{c}=\frac{G_{c}}{t_{c e}}$, shear stiffness of the concrete;

- $g_{r}=\frac{G_{r}}{t_{r}}$, shear stiffness of the resin.

$G_{r}$ and $G_{c}$ are the shear modulus of the resin and the concrete. Poisson's coefficients for both materials are taken respectively as 0.38 and $0.5 ; t_{r}$ is the resin thickness and $t_{c e}$ is the concrete thickness, calculated as suggested in [19]:

$$
t_{c e}=b_{f}+50.8 \leq \frac{h}{2}[\mathrm{~mm}]
$$

where $b_{f}$ is the width of the FRP and $h$ is the cross-section depth. The constant $50.8 \mathrm{~mm}$ represents the concrete cover thickness (2 in.). This value is an approximate average value of covers used in common bridges. Poisson's coefficient for concrete has a high value, due to the fact that the concrete is considered to be in the plastic range.

If $g_{c} \gg g_{r}$, the shear deformation of the concrete can be neglected and $g_{b}=g_{r}$, so that:

$$
L_{e}=\frac{1}{\alpha}=\sqrt{\frac{E_{f} t_{f}}{g_{r}}}
$$

The higher the FRP and adhesive stiffness the lower the debonding resistance: the parameter $\alpha$ is a good estimator of the stiffness of the system and influence of cracking in the element. Casas and Pascual's model is calibrated over characteristic values (95\% fractile).

\subsubsection{Said and $W u$ (2008)}

The FRP strain at IC debonding $\varepsilon_{d e b}$ is expressed in a general form by the following equation:

$$
\varepsilon_{d e b}=\frac{\mathrm{C} 1\left(f_{c}\right)^{\mathrm{C} 2}}{\left(E_{f} t_{f}\right)^{\mathrm{C} 3}}
$$

where $\mathrm{C} 1, \mathrm{C} 2$ and $\mathrm{C} 3$ are constants determined from experimental data. 
The compressive strength of the concrete is considered not to have a significant effect on the IC debonding, so that the high level of data dispersion, that characterizes the majority of the other proposed models, is reduced. By referring to over 200 testing data, the constants that appear in equation (8) are determined:

$$
\varepsilon_{d e b}=\frac{0.23\left(f_{c}\right)^{0.2}}{\left(E_{f} t_{f}\right)^{0.35}}
$$

where $f_{c}$ is the characteristic concrete compressive resistance. Said and Wu's model is calibrated over mean values.

\subsection{Design equation}

In order to perform the calibration of the safety factors, it is necessary, first, to set the design equations, in which the unknown safety factor $\gamma$ multiplies the whole resisting moment of the strengthened cross-section. Those design equations will also serve to derive the limit state function. The assumptions made are:

a- A plane section before loading remains plane after loading;

b- There is no relative slip between external FRP reinforcement and the concrete;

c- The shear deformation within the adhesive layer is neglected because of its thin and nonuniform thickness;

d- The maximum compressive strain at failure in the concrete is 0.0035 ;

e- The tensile strength of concrete is neglected;

f- The FRP reinforcement has a linear elastic stress-strain relationship to failure.

The flexural strengthening is obtained by bonding a FRP plate to the soffit of the beam, through prefabricated or wet-lay up systems (Table 6). The strengthening for the studied bridges is designed for both systems (Table 7). For the girder bridges, the CFRP strip is deployed underneath each girder covering the full width (one strip per girder).

Due to the T-shape of the analyzed sections, the failure of the beams will always occur by FRP debonding, after yielding of the steel. This means that the maximum IC debonding strain is the leading parameter in the design of the strengthening. 


\begin{tabular}{ccccc}
\hline System & Properties & $\begin{array}{c}\text { Elastic } \\
\text { modulus } \\
(\mathbf{M P a})\end{array}$ & $\begin{array}{c}\text { Ultimate } \\
\text { strength } \\
(\mathbf{M P a})\end{array}$ & $\begin{array}{c}\text { Ultimate } \\
\text { strain }\end{array}$ \\
\hline Precured & $\begin{array}{c}\text { Of the } \\
\text { composite } \\
\text { Wet-lay up }\end{array}$ & $\begin{array}{c}160,000 \\
\text { Of the } \\
\text { fiber }\end{array}$ & 2560 & 0.016 \\
& 230,000 & 3680 & 0.016 \\
\hline
\end{tabular}

Table 6. CFRP properties.

\begin{tabular}{ccc}
\hline Bridge & $\begin{array}{c}\text { Number of } \\
\text { strips }\end{array}$ & $\begin{array}{c}\text { Strip width } \\
(\mathbf{m m})\end{array}$ \\
\hline B10RC & 6 & 350 \\
B12RC & 6 & 350 \\
B16RC & 6 & 350 \\
B20RC & 6 & 350 \\
S10RC & 20 & 200 \\
S1015RC & 18 & 200 \\
S1520RC & 12 & 200 \\
\hline
\end{tabular}

Table 7. Characteristics of strengthening.

The general design equation (1) is expressed in the case of ULS of bending as:

$$
M_{r d}=M_{s d}
$$

$M_{s d}=$ bending moment due to actions. It is obtained multiplying the permanent loads and live load due to traffic by the corresponding safety factor as described in the Eurocode.

$M_{r d}=$ resisting moment. For the strengthened member it will take the form:

$$
M_{r d}=\gamma\left(A_{s} f_{y}(d-\varphi x)+A_{s 2} f_{s}\left(\varphi x-d_{2}\right)+A_{F} \sigma_{F} d_{1}\right)
$$


where $\gamma$ is the safety factor that needs to be calibrated; $A_{s}$ and $A_{s 2}$ are the tensile and compressive steel area, respectively (the compressive steel area is defined only for girder bridges); $A_{F}$ is the area of the composite; $f_{y}$ is the characteristic steel yielding resistance; $f_{s}$ is the characteristic tension in the compressed steel; $\sigma_{F}$ is the stress in the composite when debonding occurs, calculated according to the chosen debonding model; $d$ is the effective depth of the steel in tension; $x$ is the neutral axis depth; $\varphi$ is a coefficient which indicates the position of the force resulting from concrete compression compared to the neutral axis; $d_{2}$ is the distance between the barycenter of the compressed steel and the upper section edge; $d_{1}$ is the distance between the barycenter of the composite layer and the resultant of concrete in compression.

Concerning the design equation in bending (equation 11), it is well-known that 2 main formats are used. In the European codes and standards, the partial safety factors are defined for each material, whereas in the North-American approach, a global safety response factor affects the whole response. In the present case, the way the model error is determined (see section 2 and figure 1) suggests that the corresponding variable should be considered affecting the whole concrete-steelcomposite resisting mechanism in the corresponding Limit State Function (LSF) and design equation. Therefore, the safety factor is placed to multiply the whole resisting moment of the strengthened cross-section as described in equation 11.

As the behavior of the FRP is brittle, the ultimate strain of concrete may not have been reached when the FRP ruptures or delamination occurs. Actually this is what happens in the analyzed sections, because the debonding failure occurs before the concrete reaches the ultimate strain $\varepsilon_{c u}=0,0035$. Moreover, strains in the concrete at failure result very low for girder bridges, in the order of $0.3 \%$ o to $0.7 \%$. This means that the use of the simplified rectangular stress-block for the concrete is no longer valid. Another type of stress-strain relationship must be considered, such as the parabola-rectangle or the bilinear ones. In order to facilitate calculations a linear relation is taken, assumption legitimized by the small strain values. In fact, the simplification consists in taking a Young modulus of the concrete equal to $E_{c}=22750 \mathrm{MPa}$. This value, if the parabolic branch of the parabola-rectangle diagram is considered, corresponds to the secant modulus at the strain 0.00075 , which is the maximum concrete strain reached in the analyzed sections. The considered parabola-rectangle relation is that suggested by NTC2008 [20]: 


$$
\sigma_{c}=2 \frac{f_{c d}}{\varepsilon_{c 2}}\left(\varepsilon_{c}-\frac{\varepsilon_{c}^{2}}{2 \varepsilon_{c 2}}\right) \quad 0 \leq \varepsilon_{c} \leq \varepsilon_{c 2}
$$

where $\varepsilon_{c 2}$ is equal to $0.2 \%$.

It can be seen in figure 4, as the difference between taking the parabolic relation or the linear one is minimum. This choice is done in order to simplify the design equations, but also all the iterative procedure that involves the Monte Carlo simulation for the calculation of the probability of failure, since a parabolic relation would have been much more laborious in computational terms. The error in the simplified model is around $3 \%$ when compared with the complete model.

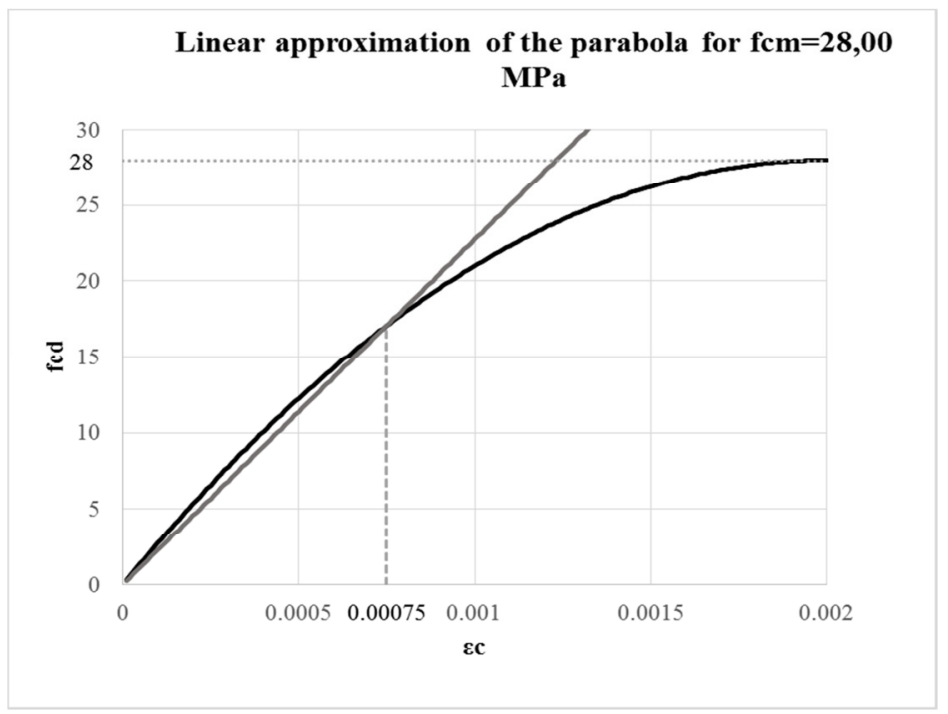

Figure 4. Linear approximation of the parabola stress-strain relation of the NTCO8 for fcd=28 MPa.

\subsection{Monte Carlo simulation}

The calculation of the reliability of the strengthened elements can be made through the definition of the LSF governing the problem and the implementation of a Monte Carlo simulation [21]. The limit state function is written as:

$$
G=M_{r}-M_{d l}-M_{l l}
$$


where $M_{r}$ is the resisting moment of the structural member, $M_{d l}$ is the acting moment due to permanent loads, and $M_{l l}$ is the acting moment due to live loads. All of them are random variables. More specifically, the resisting moment is given by:

$$
\begin{gathered}
M_{r}=\Phi\left(A_{s} f_{s}(d-\varphi x)+A_{s 2} f_{s 2}\left(\varphi x-d_{2}\right)+A_{F} \sigma_{F} d_{1}\right) \\
=\Phi\left(A_{s} f_{s}(d-\varphi x)+A_{s 2} \varepsilon_{s 2} E_{S}\left(\varphi x-d_{2}\right)+A_{F} \varepsilon_{F} E_{F} d_{1}\right)
\end{gathered}
$$

where $\Phi$ is the model error variable, $E_{s}$ and $E_{F}$ are the elasticity modulus of steel and composite; the other terms have already been explained. The modelling random variable $(\Phi)$, is also considered which takes into account the model error when estimating the flexural strength of the strengthened element via a particular model, and depends on the debonding model adopted in the design. In this case, the adopted models are the one from Said and $\mathrm{Wu}$, and Casas and Pascual. In both cases, the corresponding random variable is taken as Normally distributed with bias ratio equal to 1.0 and $\mathrm{COV}=9.2 \%$ in the first case, and a bias ratio 1.8 and $\mathrm{COV}=23 \%$ in the second. The bias and $\mathrm{COV}$ are higher for Casas and Pascual's model. The high value of the bias is due to the fact that Casas and Pascual was calibrated on characteristic values (95\% fractile), whereas Said and Wu was calibrated on mean values. This should be taken into account when interpreting the values of the partial safety factors derived in each case.

All the statistical properties of the rest of random variables participating in the limit state function (equation 13) are listed in Table 7. The concrete compressive strength appears in the limit state function through the variable neutral axis depth (x). The nominal value for the dead load is calculated based on the dimensions of the elements and the density of reinforced concrete. The bias and COV are those normally assumed for concrete elements "cast in situ" [22]. The nominal value for the traffic actions are the characteristic values of these actions according to Eurocode 1 [18], defined as the percentile of $5 \%$ for a time period of 50 years. The coefficient of variation for traffic action is taken as $20 \%$ according to [23]. The geometrical dimensions are considered as deterministic due to their low variability. 


\begin{tabular}{ccccc}
\hline Variable & $\begin{array}{c}\text { Statistical } \\
\text { distribution }\end{array}$ & Bias & COV & Reference \\
& Lognormal & & & \\
\hline $\begin{array}{c}\text { Concrete compressive } \\
\text { strength }\end{array}$ & Lognormal & Depends on compressive strength & 0.10 & {$[10]$} \\
Concrete elasticity & & (simplified model) & & \\
modulus & Lognormal & Precured: 1.05 & 0.15 & {$[1,22]$} \\
CFRP elasticity & Wet-lay up: 1.05 & 0.15 & {$[8,24]$} \\
modulus & Lognormal & 1.20 & 0.08 & {$[7,22]$} \\
Steel yield strength & Normal & 1.05 & 0.10 & {$[22,25]$} \\
Dead load & Gumbel & 0.73 & 0.20 & {$[7]$} \\
Live load & & & & {$[0.10$} \\
\hline
\end{tabular}

Table 7.- Definition of random variables

\subsubsection{Safety of the original bridges}

The reliability index $\beta$ of the existing bridges, just before any composite strengthening can be seen in Table 8. The initial reliability indexes are still quite high, even though the percent of steel lack is considerable in respect to the Eurocode requirements. This reflects the higher values of the target reliability index (in the order of 3.8) for which the Eurocode values were calibrated.

\begin{tabular}{lc}
\hline Bridge & $\begin{array}{c}\boldsymbol{\beta} \\
\text { value }\end{array}$ \\
\hline B10RC & 2,680 \\
B12RC & 2,880 \\
B16RC & 3,209 \\
B20RC & 3,482 \\
S10RC & 2,514 \\
S1015RC & 2,420 \\
S1520RC & 2,756
\end{tabular}

Table 8. Reliability index of the actual bridges. 


\subsubsection{Target reliability}

According to Table 9, the target reliability index is chosen. The table refers to a one year reference period, whereas in this work a 50 years reference period is considered. It means that the target values of $\beta$ are lower than those proposed in Table 9. As suggested in [27], the transition from a 1 year reference period to a 50 years reference period implies a decrease of the reliability factor approximately of 0.7. Therefore, placing the studied bridges in a class that can be the Moderate or Large Consequences of Failure Class and assuming a small to normal Relative Cost of Safety Measure, the target $\beta$ can be set between 3.5 and 4 . The calibration will be conducted for both the extreme values of this interval.

\begin{tabular}{clll} 
Relative cost of & \multicolumn{3}{c}{ Consequences of failure } \\
\cline { 2 - 4 } safety measure & Minor & Moderate & Large \\
\hline Large (A) & $\beta=3,1\left(p_{F}\right.$ & $\beta=3,3\left(p_{F}\right.$ & $\beta=3,7\left(p_{F}\right.$ \\
& $\left.\approx 10^{-3}\right)$ & $\left.\approx 10^{-4}\right)$ & $\left.\approx 10^{-4}\right)$ \\
Normal (B) & $\beta=3,7\left(p_{F}\right.$ & $\beta=4,2\left(p_{F}\right.$ & $\beta=4,4\left(p_{F}\right.$ \\
& $\left.\approx 10^{-4}\right)$ & $\left.\approx 10^{-5}\right)$ & $\left.\approx 10^{-6}\right)$ \\
Small (C) & $\beta=4,2\left(p_{F}\right.$ & $\beta=4,4\left(p_{F}\right.$ & $\beta=4,7\left(p_{F}\right.$ \\
& $\left.\approx 10^{-5}\right)$ & $\left.\approx 10^{-5}\right)$ & $\left.\approx 10^{-6}\right)$
\end{tabular}

Table 9. Tentative target reliability indices $\beta$ (and associated target failure rates) related to one year reference period and Ultimate Limit State [26].

\section{Results}

To obtain a set of calibrated safety factors, different strengthening designs (different values of CFRP thickness) according to assumed values of $\gamma$ are obtained and the corresponding reliability indexes are calculated. The proposed value of $\gamma$ will be that resulting in a reliability index closer to the target value. Two target values are considered: $\beta_{0}=3.5$ and 4.0.

Results found for Said and Wu's model are shown in Table 10. It can be seen that the composite thicknesses necessary to get the wanted reliability index are small for both reliability targets, and this is due to the fact that Said and $\mathrm{Wu}$ is not a very conservative model as it has been calibrated with mean values of the tests. It should be mentioned that $t_{f}$ in the case of wet-lay up systems refers 
to the fiber thickness alone and, therefore, an equivalent composite thickness should be calculated to know the real thickness of the applied system.

\begin{tabular}{|c|c|c|c|c|}
\hline \multirow{2}{*}{$\begin{array}{r}\boldsymbol{\beta}=3.5 \\
\text { Bridge }\end{array}$} & \multicolumn{2}{|c|}{ Precured } & \multicolumn{2}{|c|}{ Wet-lay up } \\
\hline & $\gamma$ & $t_{f r p}(\mathrm{~mm})$ & $\gamma$ & $t_{f}(\mathrm{~mm})$ \\
\hline B10RC & 0.839 & 0.700 & 0.838 & 0.490 \\
\hline B12RC & 0.861 & 0.640 & 0.855 & 0.470 \\
\hline B16RC & 0.893 & 0.560 & 0.887 & 0.400 \\
\hline B20RC & 0.910 & 0.500 & 0.908 & 0.360 \\
\hline S10RC & 0.899 & 0.510 & 0.893 & 0.370 \\
\hline S1015RC & 0.904 & 0.460 & 0.904 & 0.320 \\
\hline S1520RC & 0.882 & 0.750 & 0.880 & 0.530 \\
\hline$\beta=4.0$ & \multicolumn{2}{|c|}{ Precured } & \multicolumn{2}{|c|}{ Wet-lay up } \\
\hline Bridge & $\gamma$ & $t_{f r p}(\mathrm{~mm})$ & $\gamma$ & $t_{f}(\mathrm{~mm})$ \\
\hline B10RC & 0.744 & 1.370 & 0.743 & 0.960 \\
\hline B12RC & 0.766 & 1.360 & 0.764 & 0.960 \\
\hline B16RC & 0.799 & 1.320 & 0.802 & 0.920 \\
\hline B20RC & 0.828 & 1.350 & 0.825 & 0.960 \\
\hline S10RC & 0.812 & 0.900 & 0.808 & 0.640 \\
\hline S1015RC & 0.820 & 0.780 & 0.815 & 0.560 \\
\hline S1520RC & 0.790 & 1.460 & 0.790 & 1.010 \\
\hline
\end{tabular}

Table 10. Results for Said and $W u, \beta=3.5$ and $\beta=4.0$.

The final values for the global safety factor should be determined by taking into account the highest number of different design cases, in order to find a value that could be suitable to each situation. The problem in determining a value for the safety factor is that each $\gamma$ is found here by referring to a particular design case, which differs from the others for shape of the section, type of bridge, composite system and level of initial tensile steel lack. Therefore, it is difficult to choose an appropriate range of designs for the calibration of the safety factor. Anyway, the COV for precured and wet-lay up systems are very close ( 0.09 and 0.15 respectively), so that it is decided to propose 
the same safety factor for both systems. In this way, the number of the variable properties affecting the problem is reduced. As proposed even by Atadero et al. [10], the baseline for the design is defined as the amount of steel lack compared to the steel quantity needed according to the Eurocode requirements. For slab bridges the choice of this baseline comes almost natural, since they present the same percent of steel loss (32\%). Instead, girder bridges present a different percent of steel lack (going from B10RC to B20RC, 45.10\%, 30.85\%, 26.68\%, 25.20\%, respectively). Hence, they should be divided in different groups. Looking at the results obtained, it was decided to place B10RC and B12RC in two different pools $(50 \%<$ steel lack<40\%, 40\%<steel lack<30\%), while B16RC and B20RC were placed in the same group $(30 \%<$ steel lack<20\%). The final values were taken by rounding-down the found values of Table 10, when necessary. The chosen safety factors are listed in Table 11 for each design group and target reliability index.

\begin{tabular}{clc} 
Design group & \multicolumn{2}{c}{ Proposed $\gamma$} \\
\cline { 2 - 3 } & $\beta=3,5$ & $\beta=4,0$ \\
\hline B10RC (50\% < steel lack < 40\%) & 0.835 & 0.740 \\
B12RC (40\% < steel lack<30\%) & 0.850 & 0.750 \\
B16RC, B20RC (30\%< steel lack < 20\%) & 0.885 & 0.795 \\
S10RC, S1015RC, S1520RC (35\%<steel lack<30\%) & 0.880 & 0.790 \\
\hline
\end{tabular}

Table 11. Proposed safety factor for Said and Wu model.

Looking at Table 11, a more simplified proposal for the safety factors to be considered is a value of 0.85 to get a reliability index of 3.5 for almost all the bridges. A value of 0.75 is proposed to get a reliability index equal to 4 . Hence, the strength reduction factor of 0.75 , suggested by Said and $\mathrm{Wu}$ themselves [15], assures a target $\beta=4.0$ even for high percent of tensile steel loss. Therefore, the recommended value, although not based on a reliability analysis, already assured a high level of safety. The safety factor proposed by Said and $\mathrm{Wu}$ was based just on engineering judgment and available experimental results, without any reliability background. The results obtained in the present thesis confirm that the proposed safety factor derives on a too high level of safety, which is clearly uneconomical because of the high cost of the strengthening material. So the value of 0.85 , corresponding to a reliability level of 3.5 , is considered more reasonable to be applied in real cases. 
We should note that this value is much higher than the 0.6 proposed in [11] for a target reliability index of 3.25, showing the limitation of the simplified model used there, deriving on a too conservative design.

For the Casas and Pascual model it was not feasible to derive the safety factor. This can be explained if we look at the relationship debonding strain versus thickness obtained with different models. In figure 5, this relatinoship is represented for the B10RC bridge and in figure 6 for one slab bridge for five debonding models. We can see how the model of Said and $\mathrm{Wu}$ provides the highest debonding strain. We may also notice that as higher the thickness (the amount of composite needed), the lower the debonding strain, deriving on that even a higher thickness is necessary to achieve a desired resistance. It can be seen that IC debonding strain decreases very rapidly as FRP thickness increases. This happens until the thickness of the composite reaches a value more or less equal to $3 \mathrm{~mm}$. A further increase of the thickness does not lead to substantial changes in the ultimate debonding strain. Hence, the risk of incurring in debonding for high thicknesses remains almost the same after a certain value is achieved. The trend of the graph suggests that debonding failures are more likely for higher thicknesses and that a design with relatively thin FRP sheets is desirable.

This explains the fact why in some cases during the calibration it is not possible to get a solution for target reliability values higher than a certain threshold. For instance, in table 12 the reliability index of the original bridge is compared with the maximum reachable safety level using the maximum composite thickness $(5 \mathrm{~mm})$ and the Casas and Pascual model to calculate the debonding stress. The values in table 12 clearly suggest why no results become available from the calibration with target values of 3.5 and 4.0 . 


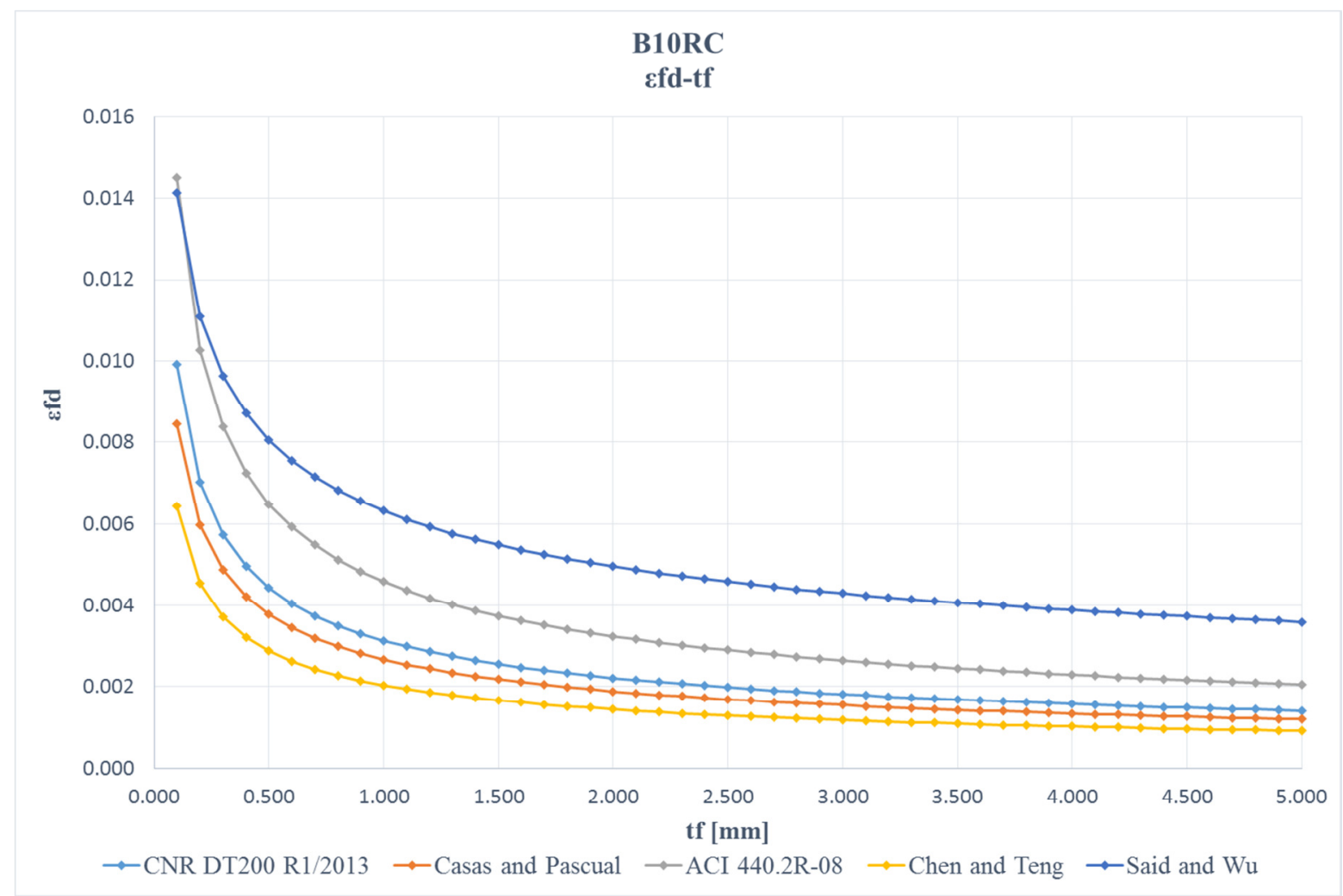

Figure 5. Debonding strain vs. composite thickness for B10RC (precured system).

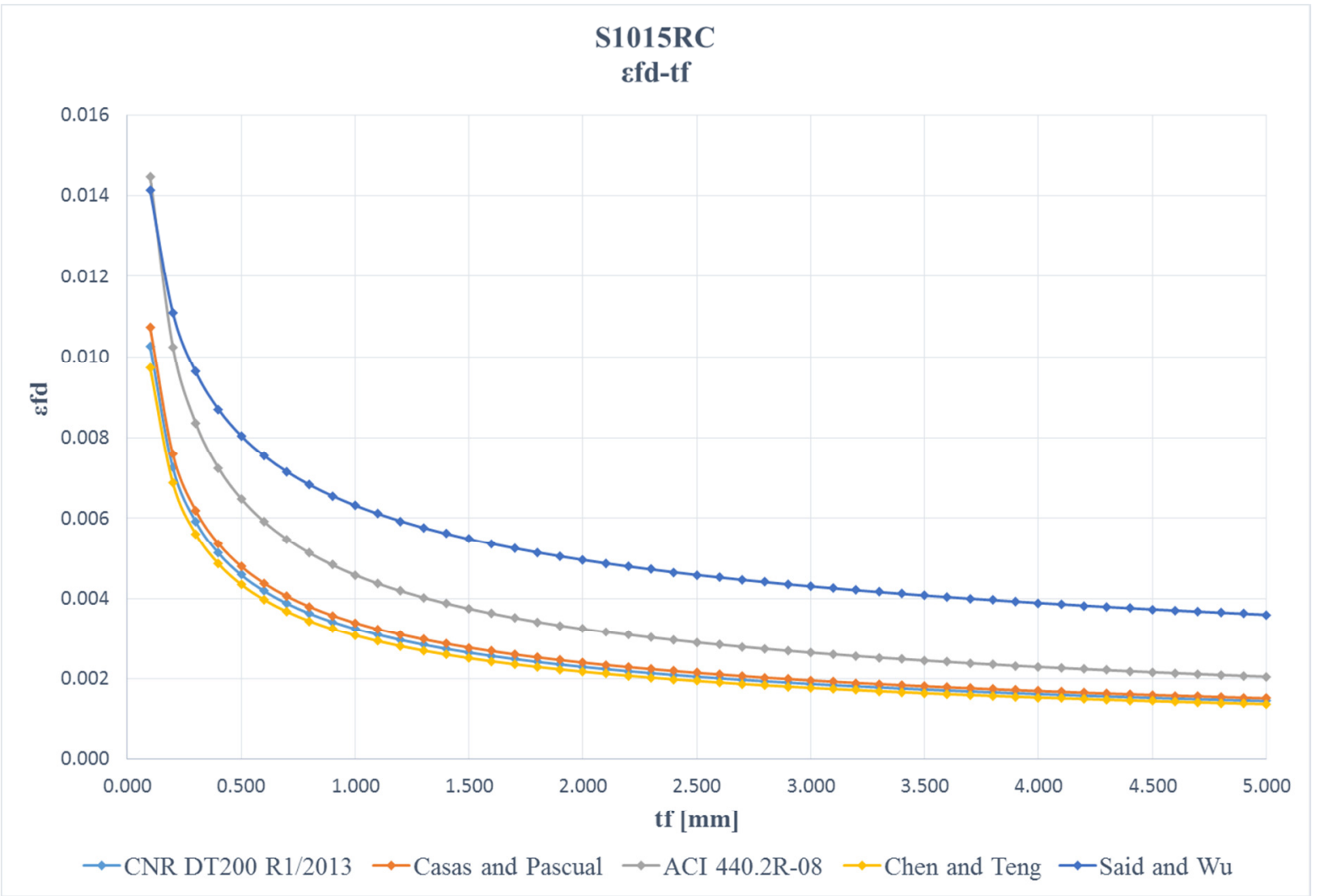

Figure 6. Debonding strain vs. composite thickness S1015RC (precured system). 


\begin{tabular}{ccc}
\hline Bridge & $\begin{array}{c}\text { Initial } \\
\boldsymbol{\beta}\end{array}$ & $\begin{array}{c}\text { Maximum } \\
\text { achievable } \boldsymbol{\beta}\end{array}$ \\
\hline B10RC & 2,680 & 3,076 \\
B12RC & 2,880 & 3,038 \\
B16RC & 3,209 & 2,951 \\
B20RC & 3,482 & 2,958 \\
S10RC & 2,514 & 3,087 \\
S1015RC & 2,420 & 3,187 \\
S1520RC & 2,756 & 3,119 \\
\hline
\end{tabular}

Table 12. Maximum achievable $\beta$ for $t_{f r p}=5 \mathrm{~mm}$ (Casas and Pascual model. Precured system).

Another remarkable issue in table 12 is the fact that in 2 cases, the reliability index of the strengthened bridge is lower than the original one, what leads to the paradox that it is safer to not strengthen the bridge. How may this be possible ? As seen, this happens for the girder bridges with the highest cross-section depth. In the original bridge at failure, the reinforcing steel is working at the yield stress with a high strain (normally limited to $1 \%$ ). The tension force in the steel is equilibrated by a small compression block at the top of the section with the concrete working at the compressive strength. However, in the strengthened bridge, the limitation of the debonding strain (around 0.2-0.3\% for large thickness) in the composite also derives in a low strain in the reinforcing steel in the same order of magnitude. Despite this low strain, the reinforcing steel still reaches the yielding stress. Therefore, to compensate the tensile force in the reinforcing steel and the composite, it is necessary a larger compression block, with the concrete working at a stress lower than the maximum compressive strength. As a consequence, the level of the neutral axis comes down and the corresponding resisting moment decreases. The increase in the tension force due to the composite does not compensate the decrease in the level arm of the resisting moment. Therefore, this phenomenon occurs because the application of the CFRP changes the failure criteria. In the original bridge the failure is reached when the concrete in compression crushes; in the strengthened beam, when the CFRP debonds. The effect is more critical as the cross-section depth is larger and the shape of the cross-section is of the T-beam type. In fact, for this section shape, due to the small web width, it is necessary to use a thick layer of composite to reach the required 
increase of resistance. In conclusion, strengthening in flexure with CFRP is not suitable in all cases and this effect should be investigated before a strengthening solution by CFRP bonding is proposed, mainly in T-shape elements with large cross-section depth as is the case of slab on girder bridges. The coefficient of variation (COV) of the debonding model also plays an important role in this behaviour. For this reason, the Said and Wu model does not present this paradox due to its lower COV compared to Casas and Pascual model. However, the trend can be observed even for Said and Wu's model, although less evidently, since the COV value is lower. In particular, it is visible when comparing the obtained composite thicknesses in case of $\beta=3.5$ and $\beta=4.0$ (Table 10). Indeed, when the target $\beta$ is fixed equal to 4.0 , the values of the composite thicknesses become almost equal for all girder bridges; results are more different for $\beta=3.5$. The needed $t_{f r p}$ for B20RC results even higher than that found for B16RC: to increase the reliability index is equivalent to set lower constraints to the admissible strains in the CFRP, and these constraints are inevitably more restrictive for cross-sections with a high depth.

\section{Importance of model error}

In the previous chapter it is shown how the model error may highly influence the design of the strengthening, provoking in specific cases the unsuitability of a CFRP application. To see the sensitivity of the partial safety factors to the model error, the results of the calibration with the model of Said and $\mathrm{Wu}$ and the model of Casas and Pascual assuming that they are $100 \%$ exact in the prediction of the debonding strain were obtained. If no model error is considered and only the uncertainties related to the materials are taken into account, then the governing equations are:

- Design equation (Design value of the resisting moment):

$$
M_{r d}=\gamma_{r}\left(A_{s} f_{y}(d-\varphi x)+A_{s 2} f_{s}\left(\varphi x-d_{2}\right)+A_{F} \sigma_{F} d_{1}\right)
$$

As before, the equilibrium equation is calculated around the point of application of the concrete compressive force.

- Limit state function (Resisting moment):

$$
M_{r}=A_{s} f_{s}(d-\varphi x)+A_{\mathrm{s} 2} f_{\mathrm{s} 2}\left(\varphi x-d_{2}\right)+A_{F} \sigma_{F} d_{1}
$$


The results obtained for a target value $\beta=4.0$ are presented in tables 13 and 14. A comparison of the two models is not straightforward for a $\beta=3.5$ because in this case, the safety requirement can be satisfied with a smaller thickness of CFRP, which is less sensitive to the debonding problem. This is particularly true in the case of the Said and $\mathrm{Wu}$ model, where for all cases except one, the small thickness of the composite necessary to accomplish the ULS of bending imposing the debonding failure mode, results in the premature failure of the composite/fiber before reaching the debonding. The terms "rupture of the composite" and "rupture of the fiber" mean that the failure occurs because the ultimate limit strength of the composite/fiber is reached. Therefore, it becomes meaningless going on with the calibration to debonding, since there are no more safety factors that need to be calibrated and the probability of failure (reliability index) is that of the rupture of the composite/fiber. This happens for Said and Wu's model more than for the other, since, it is the less conservative as it has been calibrated with mean values of the tests (see figures 5 and 6). Also, because Said and Wu model is less conservative, for similar values of the partial safety factor, the required thickness of the CFRP is much lower.

It can be seen again that the safety factors for precured systems are a little bit higher than those for wet-lay up systems. This is because wet-lay up systems have an elastic modulus with a higher coefficient of variation $(\mathrm{COV}=0.15)$, due to the larger number of uncertainties related to their application in situ. However, again as in the case where model error is considered, in practice the same safety factor may be used in both systems. A roughly value of 0.9 and 0.85 can be taken respectively for Said and $\mathrm{Wu}$ and Casas and Pascual models. This is somewhat unexpected, as Said and $\mathrm{Wu}$ model, being less conservative should, in theory, result on higher safety factors. This unlogical result is due, in fact, to not consider the model error. According to the prediction of the models (see figures 5 and 6), as the model becomes more conservative, more composite thickness is required for a certain level of strengthening as seen in tables 13 and 14 . When Said and $\mathrm{Wu}$ is applied, the calibration gives lower thicknesses for the same bridge and target $\beta$ than those given by the Casas model, since the contribution attributed to the composite is higher. A higher amount of composite means a higher contribution to the resistance in comparison to the contribution of the yielding steel. As the composite as material present a higher variability, the final result is a lower safety factor. This does not happen if the model error is taken into account. In fact, the comparison of the values in tables 10 and 13 for the Said and $\mathrm{Wu}$ model and and $\beta=4.0$ come to the conclusion about the importance of considering the model error in a reliability-based analysis. In 
the case of not considering the model error a safety factor of roughly 0.9 could be considered, which is much higher than the value of 0.75 obtained when model error is taken into account. Also, the thickness of composite required when model error is considered is almost twice the amount obtained when model error is neglected (see values of table 10 for a reliability index equal to 4.0 and values in table 13). Therefore, to introduce the model error variable together with the other uncertainties commonly adopted in a reliability analysis is indispensable to properly evaluate the reliability of the model applied and to calibrate accurately the corresponding safety factors.

\begin{tabular}{lcccc}
\hline $\boldsymbol{\beta}=4.0$ & \multicolumn{2}{c}{ Precured } & \multicolumn{2}{c}{ Wet-lay up } \\
Bridge & $\gamma_{r}$ & $t_{f r p}(\mathrm{~mm})$ & $\gamma_{r}$ & $t_{f}(\mathrm{~mm})$ \\
\hline B10RC & 0.823 & 0.790 & 0.817 & 0.580 \\
B12RC & 0.847 & 0.720 & 0.847 & 0.500 \\
B16RC & 0.899 & 0.570 & 0.893 & 0.380 \\
B20RC & RUPTURE OF THE & \multicolumn{2}{c}{ RUPTURE OF } \\
& \multicolumn{2}{c}{ COMPOSITE } & \multicolumn{2}{c}{ THE FIBER } \\
S10RC & 0.919 & 0.440 & 0.918 & 0.310 \\
S1015RC & 0.928 & 0.390 & 0.927 & 0.290 \\
S1520RC & 0.900 & 0.750 & 0.878 & 0.540 \\
\hline
\end{tabular}

Table 13. Model of Said and Wu. Results when the model error variable is not considered.

\begin{tabular}{lcccc}
\hline $\boldsymbol{\beta}=4.0$ & \multicolumn{2}{c}{ Precured } & \multicolumn{2}{c}{ Wet-lay up } \\
Bridge & $\gamma_{r}$ & $t_{f r p}(\mathrm{~mm})$ & $\gamma_{r}$ & $t_{f}(\mathrm{~mm})$ \\
\hline B10RC & 0.806 & 4.530 & 0.803 & 3.300 \\
B12RC & 0.822 & 4.230 & 0.822 & 3.000 \\
B16RC & 0.877 & 3.020 & 0.873 & 2.230 \\
B20RC & 0.913 & 2.130 & 0.912 & 1.500 \\
S10RC & 0.899 & 2.120 & 0.898 & 1.490 \\
S1015RC & 0.905 & 1.600 & 0.904 & 1.120 \\
S1520RC & 0.868 & 4.060 & 0.867 & 2.880 \\
\hline
\end{tabular}

Table 14. Model of Casas and Pascual. Results when the model error variable is not considered. 


\section{Conclusions}

A reliability-based analysis was performed to calibrate the partial safety factors for two intermediate crack-induced debonding models. The models were applied to design the flexural strengthening of seven existing reinforced concrete bridges representative of a large concrete bridge population and that present different levels of reinforcing tensile steel lack.

The performed reliability-based analysis considered for the first time the model error in the debonding model as one of the main variables participating in the Limit State Function and, therefore, in the safety of the strengthened element. The way the introduction of this variable affects the results was also discussed. The model error was placed to multiply the whole resisting moment and not just the debonding strain in the composite. For the sake of coherence, the safety factor was also placed affecting the whole resisting moment in the design formula.

Results were found for Said and Wu's model, for two target reliability indexes, $\beta=3.5$ and $\beta=4.0$. The design values for the safety factors were determined by grouping the bridges on the base of their percent of steel lack. The proposed values show that a safety factor equal to 0.75 , as already suggested by Said and $\mathrm{Wu}$ [15], assures a reliability index close to 4.0 for bridges with a steel lack ranging from $50 \%$ to $30 \%$. Note that this value is excessive for bridges that present a lower percent of steel lack. This is why, a lower value of the target reliability index in the range of 3.5 or even lower is proposed as a result of the present work, which consists on a global safety factor equal to 0.85 for both prefabricated and wet-lay up systems. This value is much higher than the 0.6 proposed in [11] for a target reliability index of 3.25, showing the limitation of the simplified model used there in performing the reliability analysis which derives in over-conservative strengthening solutions.

Therefore, the proposed design equation for the resisting moment when strengthening with CFRP in bending for both prefabricated and wet-lay up systems when the failure is due to IC debonding of the laminate, is the following:

$M_{r d}=0.85\left[A_{s} f_{y}(d-\varphi x)+A_{\mathrm{s} 2} f_{\mathrm{s} 2}\left(\varphi x-d_{2}\right)+A_{F} \sigma_{F} d_{1}\right]$

where 
- $\quad A_{S}, A_{\mathrm{s} 2}$ and $A_{F}$ are the tensile steel, compressive steel and composite/fiber areas, respectively;

- $f_{y}$ is the yielding stress of the reinforcing steel

- $\quad f_{\mathrm{s} 2}$ is the stress in the reinforcing steel placed in the compression zone

- $\quad d$ is the effective depth of the cross-section

- $\varphi$ is the ratio of the distance of the force resulting from compression in the concrete from the upper edge to the neutral axis $x$

- $d_{2}$ and $d_{1}$ are the distance of the compressive steel barycenter from the upper edge (edge in compression) and the distance of the composite/fiber barycenter to the force resulting from compression in the concrete

The strain in the composite/fiber should be calculated according to Said and Wu's model [15]:

$$
\varepsilon_{d e b}=\frac{0.23\left(f_{c}\right)^{0.2}}{\left(E_{f} t_{f}\right)^{0.35}}
$$

Being $f_{c}$ the compressive strength of the concrete and $E_{f}$ and $t_{f}$ the elasticity modulus and thickness of the composite. The position of the neutral axis can be calculated using the simplified model for the concrete stress-strain relationship for concrete as proposed in this work which is based on a linear relationship with a value of the elasticity modulus corresponding to the secant modulus at the strain of $0.075 \%$.

No results were drawn with the Casas and Pascual model when the model error is taken into account, as the high value of the coefficient of variation $(\mathrm{COV}=0.23)$ impeded to reach the reliability targets. Not only the increment of the initial reliability was little for the majority of the bridges, but also, in some cases, the final reliability was lower than the initial one. This was due to both the geometry of the considered cross-section (T-shape), and the high variability of the model. When proceeding with the calibration procedure, it was seen that, for values of the COV not higher than $0.15-0.16$, both the target indexes would have been reached, maintaining the bias ratio equal to 1.8. When the COV value got closer to 0.2 , the probability of failure increased drastically, and a reliability index higher than 3.0 was not achievable. This behavior was noticed also in Said and Wu's model, for which a reliability index of 3.5 and 4.0 could be reached up to a COV $\approx 0.15$. 
In the light of all these considerations, what emerges from the study is that:

1) A design safety factor equal to 0.85 , corresponding to a target safety level with a reliability index of 3.5 may be used when designing a flexural strengthening of reinforced concrete structural elements with Said and Wu's model for IC debonding failure

2) It is not always worth to strengthen in bending existing structures with FRPs. Indeed, if the failure mode is IC debonding and the variability of the debonding model used in the design is too high, the probability of failure of the strengthened bridge can exceed that of the original bridge. Partially this is mainly due to the fact that ultimate debonding strains are generally very low and easy to achieve. When the bridge is strengthened with the composite, the failure mode of the section is altered (from concrete crushing or steel rupture in the case of a standard reinforced concrete element to FRP debonding) and the leading design parameter becomes the FRP debonding strain, which presents very low values, easily reached in the case of T-shape cross-sections and/or large cross-section depths. In these cases, the low strain in the tensile reinforcement (both existing steel and additional CFRP) produces also a low strain in the compressed concrete and the lowering of the neutral axis and, therefore, a lower resisting moment than in the case without CFRP strengthening.

Moreover, if the applied IC debonding model is too conservative and the model error too high, then the maximum allowable debonding strain is even lower and more uncertain and it becomes really difficult to reach the wanted reliability target, even with thick composite layers.

3) The value of the safety factor is strictly related to the adopted debonding model. It varies mainly depending on if the model is calibrated over mean values or characteristic values.

4) It is indifferent to use a debonding model fitted to the mean or characteristic values of tests, as far as the model error (bias ratio and coefficient of variation) is taken into account in the calibration process.

5) A reliability-based analysis should be performed for each of the debonding models used in the available codes and guidelines, as to correctly evaluate the corresponding design safety factors. To this end, the model error variable should be statistically defined first for the different debonding models used in those codes. 


\section{Acknowledgements}

The authors want to thank the Spanish Ministry of Economy for the financial support provided through Research Project BIA2010-16332.

\section{References}

[1] Hollaway LC. A review of the present and future utilization of FRP composites in the civil infrastructure with reference to their important in-service properties. Construction and Building Materials 2010; 24: 2419-2445.

[2] Holloway LC, Teng JG. Strengthening and rehabilitation of civil infrastructure using fiberreinforced polymer (FRP) composites. $1^{\text {st }}$ ed., Woodhead Publishing Limited, 2008.

[3] Ceci A. Development of design specifications for strengthening deteriorated concrete bridge elements using externally applied FRP sheets. Master Thesis. Technical University of Catalunya. Barcelona, 2009

[4] Ceci A., Casas JR, Ghosn M. Statistical analysis of existing models for flexural strengthening of concrete bridge beams using FRP sheets. Construction and Building Materials 2012; 27(1): 490-520.

[5] Triantafillou TC, Plevris N. Strengthening of RC beams with epoxy-bonded fibrecomposite materials. Materials and Structures 1992; 25(4): 201-211.

[6] Plevris N, Triantafillou TC, Veneziano D. Reliability of RC Members Strengthened with CFRP Laminates. Journal of Structural Engineering (ASCE) 1995; 121(7): 1037-1044.

[7] Okeil AM, El-Tawil S, Shahawy M. Flexural reliability of reinforced concrete bridge girders strengthened with carbon fiber-reinforced polymer laminates. Journal of Bridge Engineering (ASCE) 2002; 7(5): 290-299.

[8] Atadero R, Lee L, Karbhari VM . Consideration of material variability in reliability analysis of FRP strengthened bridge decks. Composite Structures 2005; 70: 430-443

[9] Monti G, Santini S. Reliability based calibration of partial safety coefficients for fiberreinforced plastic. Journal of Composites for Construction 2002; 6(3): 162-167.

[10] Atadero RA, Karbhari VM. Calibration of resistance factors for reliability based design of externally-bonded FRP composites. Composites: Part B 2008; 39: 665-679. 
[11] Pahm HB, Al-Mahaidi R. (2008). Reliability analysis of bridge beams retrofitted with fibre reinforced polymers. Composite Structures 2008; 82: 177-184

[12] EN1990:2002. Eurocode 0: Basis of structural design. European Committee for Standardization (CEN), Brussels, Belgium, 2002

[13] Trentin C. Reliability-based calibration of partial safety factors for CFRP strengthening in bending of RC bridges. Master Thesis. Faculty of Civil Engineering, Padova (Italy), 2013.

[14] Casas JR, Chambi JL. Partial safety factors for CFRP-wrapped bridge piers: model assessment and calibration. Composite Structures 2014; 118: 267-283

[15] Said H, Wu Z. Evaluating and Proposing Models of Predicting IC Debonding Failure. Journal of Composites for Construction 2008; 12(3): 284-299.

[16] Teng JG, Yao J. Plate end debonding in FRP-plated RC beams II: strength model. Engineering Structures 2007; 29:2472-86

[17] Casas JR, Pascual J. Debonding of FRP in bending: Simplified model and experimental validation. Construction and Building Materials 2007; 21: 1940-1949.

[18] EN1991-2:2003. Eurocode 1: Action on structures - Traffic loads on bridges. European Committee for Standardization (CEN), Brussels, Belgium, 2003

[19] Harmon TG, Kim YJ, Kardos J, Johnson T, Stark A. Bond of surface-mounted fiberreinforced polymer reinforcement for concrete structures. ACI Structural Journal 2003;100(5):557-64.

[20] NTC2008. Norme tecniche per le costruzioni, chapters 4 and 12. Rome, Italy, 2008

[21] Melchers RE. Structural reliability analysis and Prediction. $2^{\text {nd }}$ ed., Wiley, 1999

[22] Nowak AS, Collins KR. Reliability of structures. McGraw-Hill, 2000

[23] Casas JR, Gomez JD. Load rating of highway bridges by proof-loading. Journal of Civil Engineering (KSCE) 2013; 17(3): 556-567.

[24] Atadero RA, Karbhari VM. Sources of uncertainty and design values for fieldmanufactured FRP. Composite Structures 2009; 89: 83-93.

[25] Schneider J. Introduction to Safety and Reliability of Structures. $2^{\text {nd }}$ ed., International Association for Bridge and Structural Engineering (IABSE), Zurich, 2006

[26] Diamantidis D. Probabilistic Assessment of Existing Structures - A publication of the Joint Committee on Structural Safety (JCSS). $1^{\text {st }}$ ed., RILEM Publications, 2001

[27] Ellingwood BR, Galambos TV, MacGregor JG, and Cornell CA . Development of a probability based load criterion for American National Standard A58. NBS Special 
Publication 577, National Bureau of Standards, U.S. Department of Commerce, Washington, D.C., 1980

[28] CNR-DT 200/R1/2013. Guide for design and construction of externally bonded FRP systems for strengthening concrete structures. Rome: National Research Council, 2013 